\title{
VIBRATION EFFECTS EXAMINATION OF CUSHIONS USED ON TRACTOR DRIVING SEAT
}

\author{
Musa Marul \\ Artvin Çoruh University, \\ Hopa Vocational High School Mechatronics Program, Artvin, Turkey \\ ABDURRAHMAN KarabUlut \\ Afyon Kocatepe University Technology, Faculty Mechanical Engineering, \\ Afyonkarahisar, Turkey, \\ e-mails: akumusa@artvin.edu.tr, kbulut@aku.edu.tr
}

[Received 09 August 2012. Accepted 05 November 2012]

\begin{abstract}
Vibration effect of driver's seat of agricultural tractor which works in land condition has been researched. In this research, three different cushions on driver's seat have been used. These are wool, sponge and cotton. Pad acceleration receiver is put on seat. Moreover, HVM100 tool has been used to record data. Data has been converted to graphs in BLAZE software. Statistical methods have been used in examining the graphs. In vibration isolation, ordering has been achieved as wool, cotton and sponge and without a cushion, respectively. Wool cushion has the best isolation. It is seen that data obtained from test results is appropriate according to ISO 2631 standards and scientific researches.

KEY wORDS: Driving seat, vibration, isolation of driving seat, cushion's effect to isolation.
\end{abstract}

\section{Introduction}

When historical development of vehicles is examined, horse-drawn vehicles having rigid wheel has drawn attention in terms of dynamic behaviour. In due course, wheels have been covered with rubber in order to not being damaged freight and to gain importance of passenger's comfort and vehicle body has been attached to wheel mechanism with elastic materials in order to decrease sudden impacts. Driving seat was directly attached to vehicle chassis. Most of alert forces in wheels were transferred to driver and passengers.

\footnotetext{
${ }^{*}$ Corresponding author e-mails: akumusa@artvin.edu.tr, kbulut@aku.edu.tr
} 
Sudden impact has been tried to prevent thank to these systems. However, they were not prevented because of increasing of system elasticity. Some of the most important problem that heavy duty machines, truck, tractor and so on drivers face with is vibration having low frequency road because of roughness, unbalance of rotating elements, and work of vehicle and so on. These vibrations that affect driver's all body causes drivers 'fatigue quickly, decreasing of working performance and damages to driver's health temporarily and even permanently.

When driving seat moves in vertical direction, dry rubbing happens in sitting mechanism and it increases vibration. For this reason, removing of parameters that affect free motion of sitting mechanism and glissade of motion surface by being greased decrease rubbing and they try to make vibration intensity harmless. Otherwise, dry rubbing in surfaces triggers vibration of seat and increase rubbing degree. Motile part of driving seat should move freely along all modules. Hence, vertical forces that come to driver in the direction of axis of channel must be prevented. These vibrations that have vertical direction affect driver's health negatively. If these vibration forces are decreased or removed, driver increases fatigue period and comfortable level of driving seat [1].

Researches in automotive industry have gotten on important developments in order to remove these negative effects. Motor vehicle drivers expose mechanic vibrations in their vehicles because of some road roughness arising from defective and hubbly land conditions. Physical health problems and psychological illnesses has been seen on drivers of trucks, tractors and other land vehicles that are exposed to broad-spectrum and low frequency [2].

Effects of vibration having low frequency on people are pretty much. The most important reason is that these vibrations are close to natural frequency of people's bodies and resonance phenomena happen because of that [3]. Especially, degenerative effect can be seen in backbone and nervous system depending on it or vibration on working environment may make worse present illness $[4,5]$.

Vibration having low frequency that has important effect on people's health and security should be isolated and it is reduced to a level that cannot damage. For this purpose, driving seat that can isolate vibration in agricultural tractors is used. The most effective solution in isolation of vibration having low frequency is using driving seats which have active isolation system. Hence, successful results have been achieved from this type of seats. However, this type of system is not common because of its complex structure and cost. Today, driving seat which have passive isolation system are used commonly in Turkey. These seats are adopted by tractor manufacturers because of simple structure 
and low cost. While in passive isolation system, good results are achieved in high frequency vibrations, seat natural frequency should be kept low for success in low frequency system $[6,7]$.

Suspension seat system is designed in order to absorb vibrations having low frequency in agricultural tractor. Materials having different structures should be used in order to filter vibration between driving seat and driver. Also, extra cushions should be put on driving seat in order to decrease vibration coming to driver. These cushions filter vibration having low frequency. The goal of researches carried on vibrations is to examine problems above-stated and to remove or decrease effects on health by examining reasons of them.

Therefore, precautions that increase motion comfort should be taken. Forces coming to driver are higher than other motor vehicles because agricultural tractors move in hubbly and unbalanced roads. Theoretical researches generally include mathematical methods and parameters which can be achieved by getting motion equation and by solving this equation with respect to frequency of force and also it can be achieved by getting numerical solutions. However, numerical results should be controlled with experimental methods and achieved experimental results and setting up the mathematical problem should be proved because mathematical solutions generally are simplified and slightly segregated.

In this research, precautions that increase isolation effect of driving seat have been considered. For this purpose, cushion that was made of three different materials has been used on the driving seat. While tractor was working in land, experimental data were achieved through measuring instrument. Data were evaluated by special software. Graphs were commented by using statistical methods after data were achieved. It was seen that wool cushion has the best isolation and without a cushion has the worst isolation. Level of vibrations of cushions that are used on driving seat filtrate and vibration values coming to driver were researched. For this research, 4 different experimental data including 3 different cushions made of cotton and sponge and natural state of seat were achieved.

\section{Experimental Setup}

In preparing of experimental setup, first of all two alkaline batteries were put in HVM100 instrument and it became portable. In order to gain measurement pad accelerometer was put on tractor seat. Measurement was achieved in two different conditions. In the first condition, there is no cushion and in the second condition, there is cushion. Cushions used in research have 


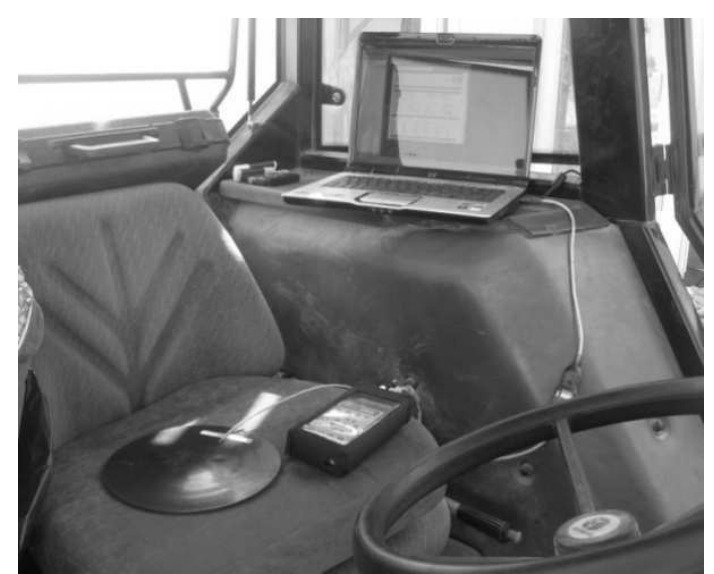

Fig. 1. The driver's seat vibration measurement

driving seat measure and it has $6 \mathrm{~cm}$ thickness and it was made of three different materials. Graphs were transformed to values thank to a special software by computerizing data in HVM100. Acceleration graphs depending on time are achieved. Statistical methods were used to evaluate them because these graphs were taken in different road roughness values.

\section{Theoretic Approach}

Vibration model of driver's seat of tractor is installed. In vibration model, cushion is presented by isolation matters. Vertical displacement of driver's seat will be examined. $m_{2}$ which is mentioned in vibration model is weight of driver. Seat model in Fig. 2 behaves vibration motion having two degree of freedom. Motion equality is written as:

$$
M \ddot{x}+C \dot{x}+K x=0 .
$$

In this equation, $M, C$ and $K$ have matrix form. $K$ is spring matrix. In matrix form, this is written as

$$
K=\left[\begin{array}{cc}
k_{1}+k_{2} & -k_{2} \\
-k_{2} & k_{2}
\end{array}\right] \text {. }
$$

$C$ is matrix having damping constant and it has same form. Matrix $M$ is symmetric and diagonal matrix:

$$
M=\left[\begin{array}{cc}
m_{1} & 0 \\
0 & m_{2}
\end{array}\right] .
$$


If this is written in the equation (1),

(4) $\left[\begin{array}{cc}m_{1} & 0 \\ 0 & m_{2}\end{array}\right]\left[\begin{array}{l}\ddot{x}_{1} \\ \ddot{x}_{2}\end{array}\right]+\left[\begin{array}{cc}c_{1}+c_{2} & -c_{2} \\ -c_{2} & c_{2}\end{array}\right]\left[\begin{array}{c}\dot{x}_{1} \\ \dot{x}_{2}\end{array}\right]$

$$
+\left[\begin{array}{cc}
k_{1}+k_{2} & -k_{2} \\
-k_{2} & k_{2}
\end{array}\right]\left[\begin{array}{l}
x_{1} \\
x_{2}
\end{array}\right]=\left[\begin{array}{l}
0 \\
0
\end{array}\right] \text {. }
$$

After some arrangements, differential equation is achieved.

$$
\ddot{x}_{i}+2 \xi_{1} \dot{x}_{i}+\omega_{i}^{2} x_{i}=0 .
$$

In this equation, $\xi$ is the rate of damping. Equity is $0<\xi<1$, solution of (5).

$$
x_{i}(t)=A_{i} e^{-\xi_{i} \omega_{i} t} \sin \left(\omega_{d i}+\Phi\right) .
$$

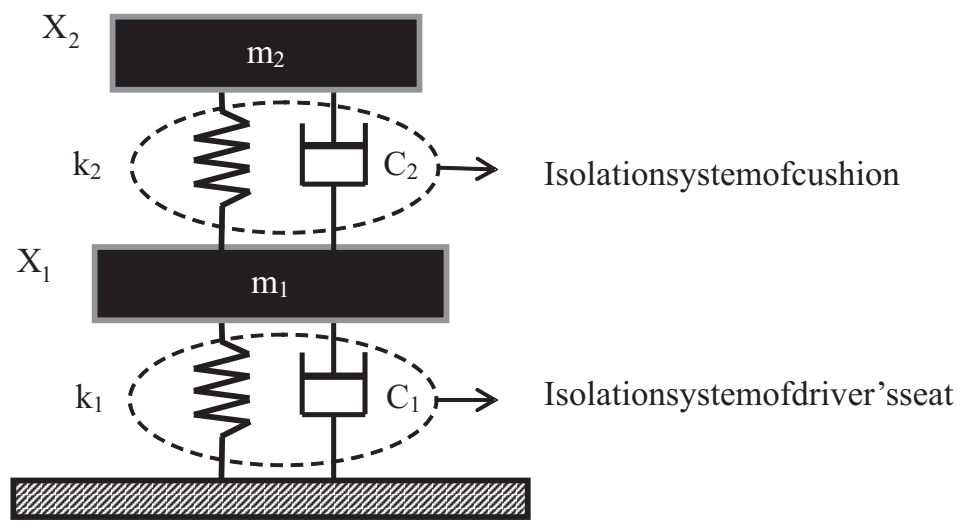

Fig. 2. Vibration model of driver's seat

Here, $x(t)$ which has sinking periodic motion has displacement vibration $A$ and $\Phi$ are constants, is freedom number and in the equation $t=2, \omega_{d i}$ is damping natural frequency. Damping natural frequency depends on property of material [8]. In equation (6), calculation is numerically performed in both seat isolation system and isolation system of cushion.

\section{Findings}

It was seen, that cushions that have different properties have positive effects on driver. Cushion made of any material has more supportive than cushionless in terms of isolation. Moreover, isolation rate can change by material property. In three cushions made of wool, sponge and cotton used in this 
research, cushion made of wool is the best isolation material. The purpose is to decrease vibration intensity of driving seat, to increase comfort and to increase fatigue period of driver. The most determiner factor in tractor vibration is acceleration value. When driver exposed to alert forces, acceleration motion was calculated in vertical direction

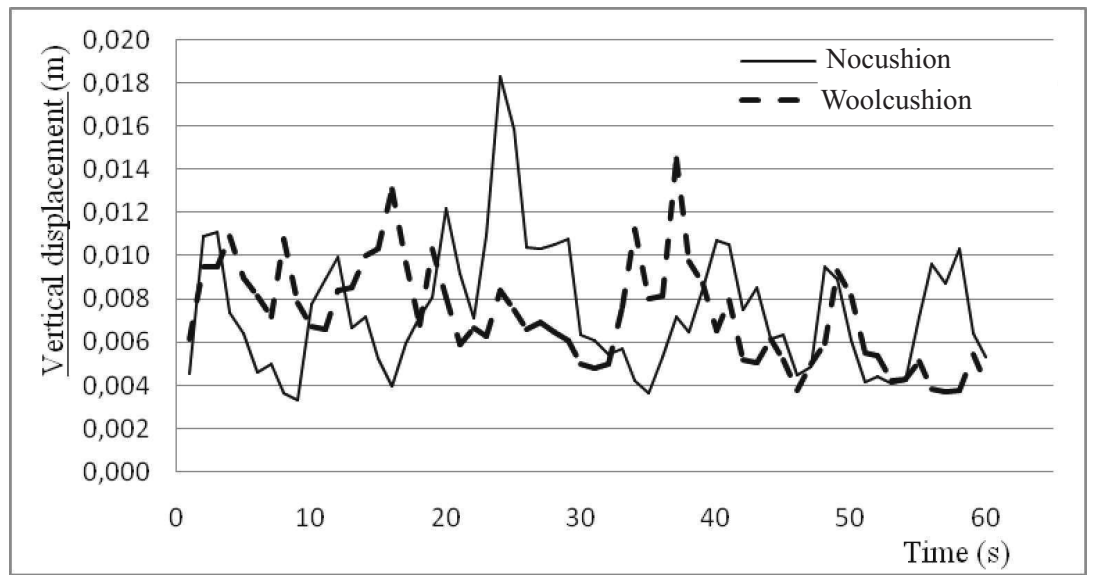

Fig. 3. Vertical displacement graph of cushionless and wool cushion

Time depended vertical displacement of cushionless and wool cushion is showed in Fig. 3. Curves of graph are converted to periodic motions in FFT transformations. Unknown parameters may be found by using equations.

Vibrations coming to driving seat were recorded with one minutes' periods while tractor was working. Separately, graphs were achieved for every cushion. In evaluation of them, finding of vibration magnitude is not possible normally because same road roughness were not used. Vibration isolation values were achieved by using coefficient of variation as statistical method.

Coefficient variation of graph is bigger in cushionless. It shows that fading of seat is weaker. Cushion contributes to fading of seat. Decreasing of value that will peak suddenly in acceleration curves shows that cushion contributes to seat isolation. In Fig. 4(b), it is shown peak value in acceleration with cotton cushion. The reason for this is that tractor hits strong vibration or swell when tractor is working. Same condition is shown around $20^{\text {th }}$ second in Fig. 4(c). These values are shown in Table 1. In Fig. 4, acceleration curves of seat vibration of three cushions without cushion is showed. Differences are not shown by comparing curves because tractor was used in different road roughness. In order to understand these graphs vibration magnitude can be found by using statistical method. 


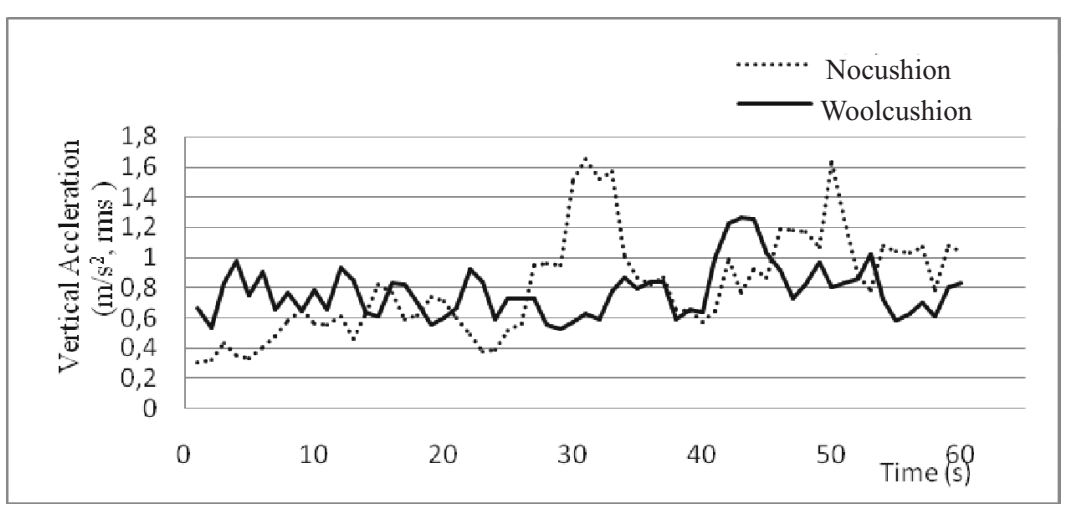

(a)Nocushionandwoolcushion

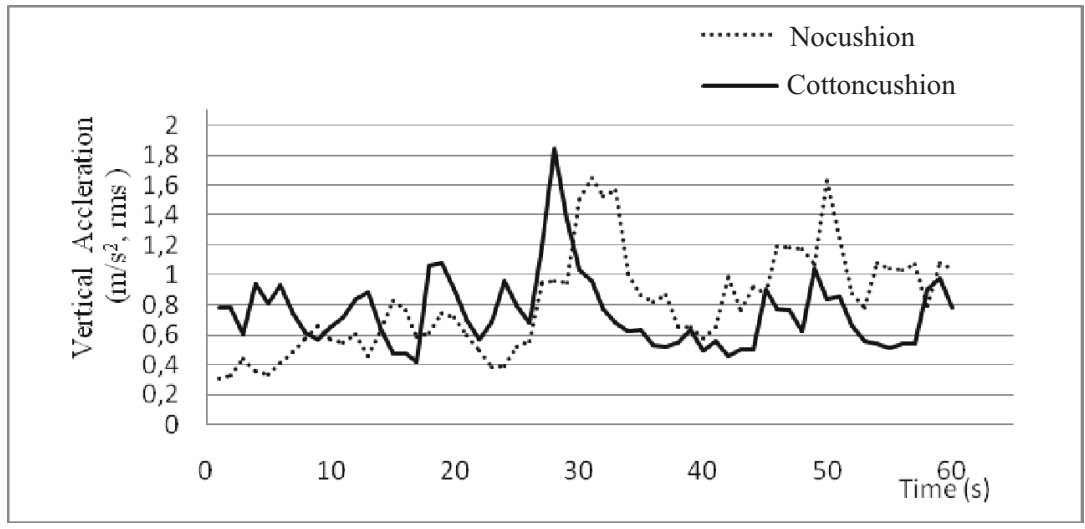

(b)Nocushionandcottoncushion

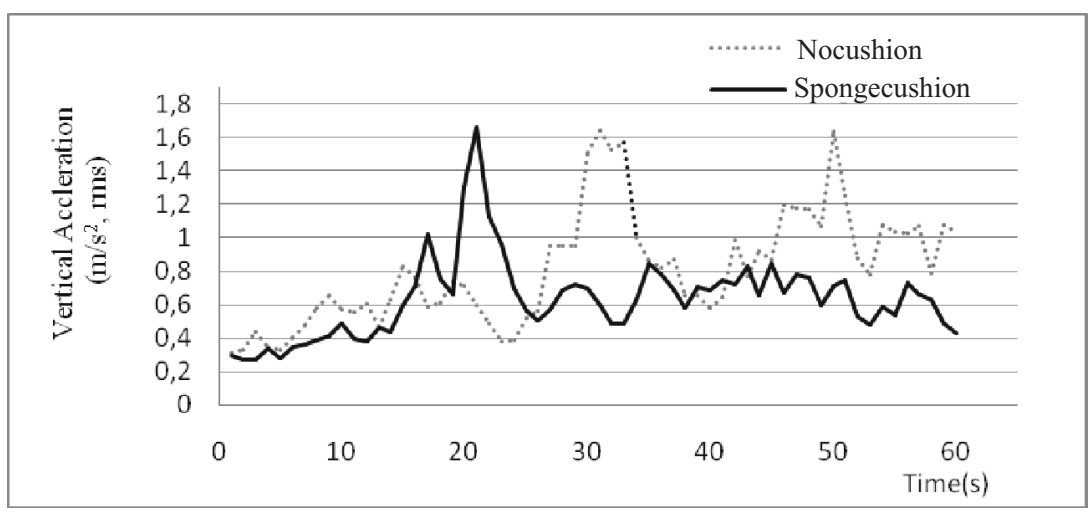

(c)Nocushionandspongecushion

Fig. 4. Acceleration graphics 
Table 1. Cushion values

\begin{tabular}{|l|c|c|c|c|}
\cline { 2 - 5 } \multicolumn{1}{c|}{} & \multicolumn{4}{c|}{ Types of Cushion } \\
\hline Method & Wool & Cotton & Sponge & Cushionless \\
\hline Standard Deviation & 0.17047 & 0.24810 & 0.24464 & 0.33813 \\
\hline Coefficient of Variation & 22.0460 & 33.1020 & 38.6450 & 41.4920 \\
\hline
\end{tabular}

It is stated, that wool cushions has better isolation than cushions made of other materials and scientific researches, every wool wire forms of three dimensional spiral curve and each of them has miniature spring duty. If coefficient of variation is examined, isolation value of wool cushion is the best with 22.0460. Therefore, it is seen that wool material is more sufficient for vibration isolation in Fig. 5, shown below:

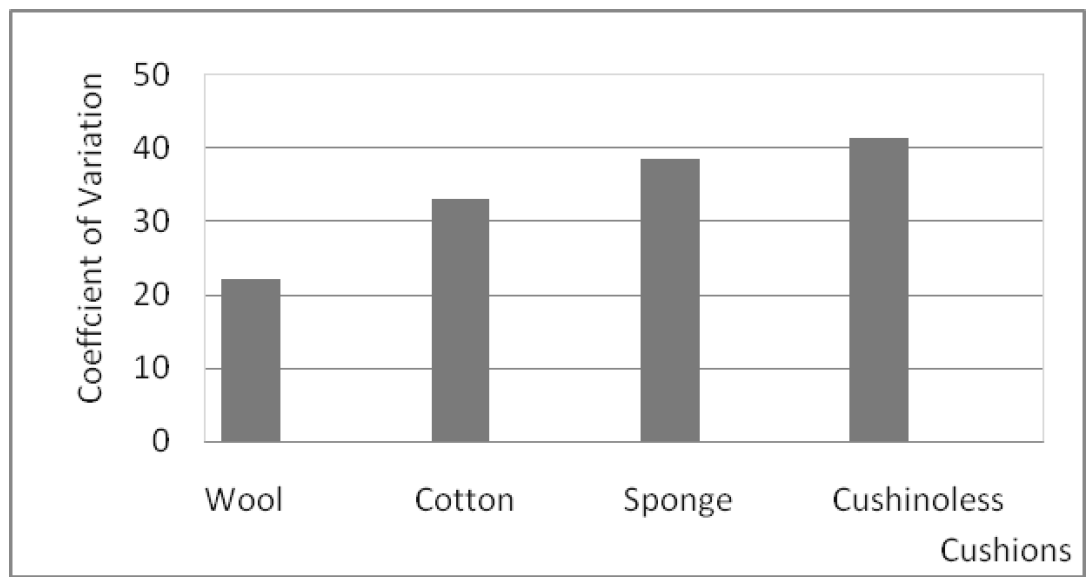

Fig. 5. Conductivity values of cushions

\section{Graphics}

When tractor was working, acceleration values taken from seat is shown in Table 2. In graphics, vertical axis is acceleration and horizontal axis is time. Data were recorded in one minutes' period. Time is the same for the three graphics.

Graph curves are different because of the different roads. Statistical method was used in order to find which cushion has better vibration isolation. Standard deviation and coefficient of variation was achieved by using numerical 
values of graphics.

$$
\text { Standard deviation }=\sqrt{\frac{\sum_{i=0}^{n}\left[x_{i}-\bar{x}\right]^{2}}{(n-1)}}
$$

$\bar{x}=$ Arithmetical average;

$n=$ described as number of data;

In order to find coefficient variation equation used in standard deviation calculation can be benefited from standard as described in Equation (8).

It is found with

$$
\text { Coefficient of variation }=\frac{\sqrt{\frac{\sum_{i=0}^{n}\left[x_{i}-\bar{x}\right]^{2}}{(n-1)}}}{\bar{x}} \times 100 .
$$

Equation (8) gives truer result about vibration magnitude. In cushionless acceleration curves, standard deviation 0.33813 and coefficient variation is 41.4920. In wool cushion acceleration curves, standard deviation is 0.17047 , coefficient variation 22.0460. In cotton cushion acceleration curves, standard deviation is 0.24810 , coefficient variation is 33.1020 . In sponge cushion acceleration curves, standard deviation is 0.24464 , coefficient variation is 38.6450 .

According to these results, standard deviation and coefficient variation of wool cushions is less than other cushions. Standard deviation states changes. Thus, if variability will be less, vibration will decrease with same ratio.

In order to determine vibration magnitude, coefficient variation is another numerical value. We can find coefficient variation with the help of Equation (8). Coefficient variation varies with respect to average. Coefficient variation of cushions are 22.0460 for wool, 33.1020 for cotton, 38.6450 for sponge and 41.4920 for cushionless, respectively. It is seen that variable value is in wool cushion with respect to least average and the most variable is in cushionless.

\section{Results}

Research has been carried about decreasing vibration effect of cushions made of different materials on driving seat in land conditions. Tractor producing low frequency between $1-10 \mathrm{~Hz}$ is a vehicle. People's entrails like waist and stomach has $1-10 \mathrm{~Hz}$ as natural frequency values. Driver may be damaged permanently in the condition of resonance. Vibration isolation on driving seat is important. 
In experimental study, cushion that was made of three different materials has been used on driving seat and vibration isolation has been measured and from the best isolation to the weakest cotton, sponge and cushionless, respectively. Vibration isolation of wool cushion is more comfortable and higher than cushionless driving seat and it is shown with numerical values. It is seen, that cushions made of cotton and sponge is better than cushionless driving seat in terms of vibration isolation. In vibration isolation, wool material is better than other materials because it has elastic and energy-absorbing properties. It is seen, that any elastic, soft material used on driving seat contributes to vibration isolation. Also, it is seen, that numerical values found matches with ISO 2631 standards.

\section{REFERENCES}

[1] Karabulut, A. An Investigation on Vibrational Isolation of Tractor Seats, Ph.D. Thesis, Gazi University, Institute of Science, 1995.

[2] Rakheja, S., S. Sankar. Improved Off-road Tractor Ride via Passive Cab and Seat Suspensions, Design and production engineering technical conference of the American society of mechanical engineers, Dearborn, 1983, 305-313.

[3] Sabanci, A. Ergonomics, Adana, Baki Bookstore, No. 13, 1999.

[4] Anonim. Mechanical Vibration and Shock-Evaluation of Human Xposure to Whole-body Vibration, International Organization for Standardization 2631-1, Switzerland, 1997.

[5] Griffin, M. J. Vibration and Motion. Handbook, Humman Factors and Ergonomics, A Willey-Interscience Publication John Willey \& Sons Inc., 1997, $828-857$.

[6] OraK, S. Constructive Measures for Increasing Comfort Chairs Tractor Driver, Ph. D. Thesis, Anadolu University, Institute of Science, 1989.

[7] Eye, S. A. Evaluation of Operator Whole- Body Vibration and Shock Exposure in a South African Open Cast Mine, Master of Science, University of Pretoria, Faculty of Engineering, Build Environment and Information Technology, 2009.

[8] Inman, D. I. Engineering Vibration, London, Pearson Education, 2008. 